\title{
Optimisation of Water Absorption Parameters of Bagasse, Cocoa Pod Husk and Guinea Fowl Feather Reinforced Hybrid Epoxy Composites using Taguchi Method
}

\author{
${ }^{1}$ Chris Abiodun Ayanladun, Sunday Ayoola Oke* \\ Department of Mechanical Engineering, University of Lagos, Lagos, Nigeria
}

\begin{abstract}
Particulate waste of bagasse, cocoa pod husk and guinea fowl feathers may be adopted to fabricate epoxy composites due to their properties of biodegradability, lightweight and cheapness. However, most research has excluded the combination of these reinforcements while the optimisation behaviour of the reinforced composites at room temperature water absorption process is not known. To fill this knowledge gap, this paper aims to analyse issues related to optimisation of the mentioned reinforced composites considering Taguchi's L25 orthogonal array, the smaller the better signal-to-noise criterion and remodelling of signal-to-noise ratio after the exponential smoothening structure for optimisation. The experiment considered $25 \%$ reinforcement blends to $75 \%$ epoxy resin. But the $25 \%$ reinforcement had five formulations among the component reinforcements. The experiment, using tap water, was conducted for 216 days with measurement intervals random. The response table yielded $A_{5} B_{5} C_{4}$, indicating 158 experimental days, $12.29 \mathrm{~g}$ of weight gained by the drained composites and $7.32 \mathrm{~g}$ of weight gained by composites damped in $190 \mathrm{ml}$ of water. The revised response table that has been influenced by the exponential smoothening method yielded $A_{5} B_{5} C_{5}$, interpreted as 158 days of experiments, $12.29 \mathrm{~g}$ of weight gained by the drained composites and $7.44 \mathrm{~g}$ of weight gained by composites dumped in $190 \mathrm{ml}$ of water. Using the damping factors from 0.05 to 1 , different combinations as optimal parameters were obtained, assuring the investigator that the method is feasible. Thus, the optimisation assessment could provide a new method of combining the reinforcement to enhance the composite development process using waste.
\end{abstract}

Keywords: Reinforcement, Optimisation, Water Absorption, Particulates.

\section{Introduction}

Sustainable utilisation of produce and animal waste for high integrity structures has been the goal of sustainability campaign towards attaining a positive change in practice in recent times $[1,2]$. The prime attention is to achieve the needs of the present time while permitting future generations to achieve their needs regarding the economic, environmental and social aspects of practice [2]. In this context, particulate waste of agricultural products such as cocoa pod husk and bagasse, together with bird's feathers [3], such as the guinea fowl feathers may be adopted to fabric ate epoxy composites due to their properties of biodegradability, lightw eight and cheapness [4-10]. In doing this, optimisation should be a key driver and should mainly responsible for selecting the best combination of these reinforcements in the epoxy resin to enhance water absorption properties [11, 12]. Further, a supporting issue is to understand how the different values of the input reinforcements influence the values of water absorption properties of the hybrid composites developed.

\footnotetext{
* Corresponding author. Tel.: +234-8058179170

E-mail address: sa_oke@yahoo.com

Manuscript History:

Received 6 February, 2021, Revised 21 April, 2021, Accepted 21 April, 2021, Published 30 April, 2021
}

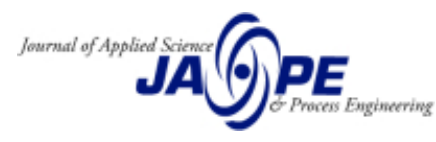


Unfortunately, most research has excluded the combination of these reinforcements while the optimisation behaviour of the reinforced composites at room temperature in the water absorption process is not known. The composite industry is one of the most dynamic sectors in the economy in the past few years and an anticipated all-time high is expected in the demand for agro-based composites in the next years [13-15]. Consequently, there is a need to have a clearly defined optimisation goal for the reinforcements to be used by combining cocoa pod husk, bagasse and guinea fowl feather with epoxy resin for composite fabrication. Furthermore, the responsiveness of these inputs to change in outputs should be understood. This information is needed so that the composite developer could work effectively on the limited resources and offer composites of high integrity with water absorption resistance. Due to the government support for agriculture, an increase in the production of bagasse, cocoa pod husk and guinea fowl feathers is expected in the coming years but there is no way of easily determining how this information will enhance the optimisation outcomes.

The idea of this study was to improve understanding of the optimisation procedure for the input reinforcement and the epoxy resin of the hybrid composites developed as a basis for adequately opportunity the input materials in an economic combination to avoid resource wastage. However, a simple ratio analysis alone may be insufficient to establish the optimisation procedure. Consequently, the Taguchi method is deployed to effectively analyse the problem by first establishing the principal driving factors in the water absorption process as (1) time of the experiment, which is expressed in days (2) weight gained by composites, expressed in grammar and (3) weight gained by composites damped in $190 \mathrm{ml}$ of water, expressed in grammar. Based on the gathered data, levels are defined on a convenient scale that matches the threshold of the collected data. An orthogonal array is then chosen which matches the factors to the defined levels of the factor data.

Next, based on the choice of one criterion from a list of three, a signal-to-noise ratio is established. The list consists of first, the smaller-the-better criterion, next, the nominal-the-best criterion and lastly, the larger-the-better criterion. From the list of defined experimental trials calculated based on the selected signal-to-noise criterion, the response table is produced by summarizing the actual values of the signal-to-noise values. For each level in a factor, the corresponding signal-to-noise ratios are average for all possible signal-to-noise values. The optimal parametric setting is then selected which serves as a basis upon which new formulation involving the input reinforcements are made. The scopes of this research entail the following: (1) study the influence of water absorption process parameters on the response pending attainment of optimum parametric setting through the Taguchi experiment; (2) applying the proposed Taguchi method with modified response table generation method to three important parameters such as the time of the experiment, weight gained by drained composite, and weight gained by composite damped in $190 \mathrm{ml}$ of water; (3) analysing validating the Taguchi method's performance by collecting new experimental data on hybrid bagasse-cocoa pod husk guinea fowl feather epoxy composites on the conducted experiment in the laboratory; and comparing the optimal parametric setting of the Taguchimethod with computations from the signal to noise ratios through the introduction of exponential smoothening methods with damping factors.

The objective of this study is to establish the optimal parameters of a newly developed composite, an agro-waste reinforce composite comprising of bagasse particles, cocoa pod husk and guinea fowl feathers in the powdered form embedded in the epoxy matrix at room temperature underwaterabsorption condition. Furthermore, this paper aims to analyse the optimisation issue associated with the insertion of hybrid bagasse, cocoa pod husk and guinea fowl feathers composites in tap water. To tackle some concerns related to water absorption process parameters of the mentioned hybrid composite, the considered parameters are the time of the experiment, weight gained by drained composites and weight gained by composites damped in $190 \mathrm{ml}$ of water. To establish the parameters of the water absorption process, a Taguchi method that employs an orthogonal matrix in an experimental design system is deployed. The authors are unaw are of a study in the composite or water absorption literature aiming to optimise combined bagasse particles, cocoa pod husk powder and powdered guinea fowl feathers in water experiments. The water absorption parametric determination problem using the Taguchi method has been established in this work. Consequently, the work presented in this research offers a new contribution to the composite as well as the water absorption literature in composite development. 


\section{Literature review}

\subsection{General}

The water absorption process in hybrid epoxy composites is a three-dimensional mechanism and phenomenon, consisting of the diffusion process, capillary and water molecule transport. The degree of each mechanism for a composite dictates the amount of water absorbed, calculated as the proportion of the weight of water absorbed (top or seaw ater) to the weight of the new ly fabric ated hybrid composite before, immersion. In this article, water absorption involves hybrid composites made from (1) bagasse particles, (2) cocoa pod husk particulates, and (3) guinea fowl feathers.

Bagasse is the residue of sugarcane after extracting the sugarcane juice from the plant $[9,12,16$. Coupled with its abundance, being biodegradable to full compost in roughly 45-60 days, and its renewable eco-friendly nature with the capability of being reproduced in cycles within one year [17], bagasse was taken as a choice reinforcement in the hybrid composite considered in this article. The cocoa pod husk, which is obtained from cocoa as a waste by-product, is the final output when the cocoa beans are removed from the fruit. By dimension, a cocoa pod may have lengths of roughly 7 to 8 inches. However, the rind is often from 0.79 to 1.18 inches while its thickness varies with the origin and variety being the major determinants of the pod's thickness. How ever, its biodegradability and renew ability are two key issues that motivated the present researchers to adopt cocoa pod husk as reinforcements to the hybrid composite produced. The guinea fowl feathers are from birds of the other and family "Numididae" and "Galliformes", respectively. The guinea fowl feathers may have a common size of 6 to $10 \mathrm{~cm}$ in size. A variety may have characteristic while dotted round colour pattern. Often called the polka dot configuration, with the background of black or brown, it is tough and resistant to water and hence is an attractive reinforcement with large potentials for hybrid epoxy composite development.

Of these three reinforcement used in this article, namely, bagasse particles, cocoa pod husk particulates and the guinea fowl feathers, the last mentioned is unique and has not been found as a reinforcement to epoxy composites in the literature. Yet it has huge potentials as available reinforcement for hybrid epoxy composites. For engineering applications, Abubakar et al. [18] were the first researchers to examine the guinea fowl feathers and called for intensive research on this reinforcement. From their perspective, there is huge potential to consume guinea fowl feathers in new material development and the Nigeria poultry industry was raised as the first source of guinea fowl feathers for material fabrications. The use of feathers as reinforcement for composites may have been around for a long time. For example, Verma et al. [19] experimentally investigated the mechanical and Microstructural behaviour of chicken feather fibre embedded in the hybrid composite. The conclusion from the research was that $1 \mathrm{wt} \%$ of chicken feather fibre composite revealed the utmost outc ome within the tested options.

There are other compelling examples of applications of chicken feathers in composites development. The studies by Oladele et al. [20], Taghiyari et al. [21], Zhan and Wool [22] and Bansal and Singh [3] are a representation of the progress made in composite fabrication using chicken feathers as reinforcements. The consensus of opinions from these studies on chicken feathers composites is that outstanding mechanical properties were demonstrated by composites with chicken feathers as reinforcements. These mentioned fascinating examples that demonstrate success with the fabrication of chicken feather, reinforc ed composites raise some interesting question for composite researchers. For instance, can the guinea fowl feathers be used to reinforce epoxy composites with success? Could bagasse be combined with it? What about making a hybrid epoxy composite with success having particulate bagasse, pow dered cocoa pod husk and particulate guinea fowl feather? In this article, the authors focus on the last interesting question: What about making a hybrid epoxy composite with success having particulate bagasse, powdered cocoa pod husk and particulate guinea fowl feathers?

There is a well-grounded research tradition in the composite development area to explore such questions suing mechanical and microstructural tests involving X-Rays distraction, atomic absorption spectrophotometer and scanning electron microscopy, tensile and hardness tests. However, more pressing in the economy of some developing countries with seaports is to expand new material 
development to interface with water bodies. Besides, the current literature has often neglected waterbased studies when composite development based on chicken feathers was tackled. Consequently, at variance with the current literature, the developed hybrid composite, consisting of particulate bagasse, cocoa pod husk and chicken feathers as reinforcement; was tested underwater absorption process, particularly using tap water. The article deals with the question by drawing primarily on experiments and then Taguchi analysis.

From the problem definition, it is conceived that the literature that may reveal the gap is the bestreviewed by analysing the literature from the following areas: (1) Taguchi studies on composite development (2) bagasse composite and (3) cocoa pod husk composites.

\subsection{Taguchi studies on composite development}

In Taguchi experimentation, the aim is to minimise the effect of instance factors and permit comparisons among the important parameters, thus aiding the fabric ation of quality hybrid composites from the component reinforcements, namely the particulate bagasse, cocoa pod husk and powdered guinea fowl feathers. But the literature has been conducted on several other composites aside from the hybrid composite discussed here. For instance, interest was should in the deployment of the Taguchi method by Suherman et al. [23] to model the substantial parameters of moulding process time, temperature and pressure regarding the development of carbon black/graphite-epoxy composite. It was concluded that time showed a distinctive influence on the system. In Kiran et al. [24], the L9 orthogonal array was used to enhance the tensile strength of glass fibre composite. Taguchimethod in its application detected that fibre direction was the most impactful factor in the system.

In Pang et al. [25], the parametric optimisation of dry halloysite nanotube, as well as aluminium reinforced epoxy composite, was discussed. The Taguchi method declared the most advantageous parameters from the list, including feed rate, depth of cut and cutting speed. Also, some studies have not deliberated or optimisation, the analysis carried out in them implies the search for the best parameter of a constituent in the composite, which is a form of optimisation studies reports along the direction include Bagci and Imrek [26], Costa et al. [27], Wang et al. [28], Fiho et al. [29] and Ige et al. [30]. Bagci and Imrek [26] were concerned with the best choice of options in a wash-away proc ess concerning combined boric acid, glass fibre and epoxy resin with specific interest on the influence of velocity, fibre orientation and size on the introduction of aluminium partied into the composite Costa et al. [27] was concerned with the influence of constituent strengthening on the mechanical abilities of the composite. Wang et al. [28] and Fiho et al. [29] were independently interested in the Brazilian palm tree and woven glass epoxy composite respectively. Ige et al. [30] showed interest in disc brake composite.

This part of the literature review has shown the significance attached to optimisation by the composite community but also the gap that no study has applied Taguchi optimisation to any composite developed with guinea fowl feather or its hybrid, to be best of the authors' knowledge. But permitting this gap to remain opened continues to deny the composite community of the benefits of Taguchi experimentation, including cost reduction and quality improvement.

\subsection{Bagasse composites}

Since bagasse reinforcement is one of the reinforcements utilized in this study, screening the bagasse composite literature for similar studies to the present one is essential. Briefly, composites studies on bagasse reinforc ement have grown tremendously over the years. The foresight of Loh et al. [31] to declare bagasse composite as a future material given the enormous potentials it has in several sectors of the economy such as building materials, energy applications, pumps and interior decorations is almost a reality and the predictions that numerous bagasse-based composites and structure would emerge after the year 2013 may be said to be partially fulfilled now. The authors examined the use of 
bagasse in its original and treated forms. Besides, the different manipulation technologies were analyzed. Xiong [32] reviewed the sugarcane bagasse composite literature and established the parameters that impact their characteristics. The impacts and mechanisms of these parameters were studied. The author summarized the superior mechanic al properties of the various bagasse composites, including their attaining situations and the durability of the composites. Devadiga et al. [16] also reviewed the literature focusing on developmental trends, features of bagasse composites, diverse chemical modifications on bagasse composites and processing methods to enhance the acoustic, ageing, thermal and mechanical attributes of bagasse composites.

Vidyashri et al. [33] prepared chemic ally modified bagasse fibre and tested it using various tests, including scanning electron microscope, X-ray distraction and thermogravimetric analysis. It was concluded that alkali-treated and $\mathrm{KMNO}_{4}$ treated fibres revealed enhancement in thermal and mechanical attributes. Although within the composite domain, but outside the epoxy matrix usage, Kumar et al. [34] introduced bagasse as a reinforcement in an aluminium metal matrix composite. It was revealed that bagasse powder fortified composites could yield improved properties at reduced densities. Undoubtedly, the literature on bagasse composites is robust with extensive deliberations on important properties, including thermal, water absorption, mechanical, fatigue, flexural and hardness. Besides, microstructural tests, including X-ray distraction and thermogravimetric analysis have proved the rigour of experiments conducted in the bagasse composite area. Unfortunately, despite the extensive reports, there is no single study that has blended guinea fowl feathers with bagasse reinforcement and other reinforcements. This keeps the composite community surprised that nothing has been done concerning the novel composite reinforcement, guinea fowl feathers despite its huge potentials.

\subsection{Cocoa pod husk composites}

To the best of the authors' knowledge, two notable research groups dominate the research scene on cocoa pod husk composite development and testing. These groups involve Imoisili and workers as well as Chun and workers. The major focus on Imoisili and workers in the development of cocoa pod husk composites and testing underwater environment and testing of properties under change effects of a variable. Imoisili et al. [35] studied the mechanical characteristics of fabric ated composites reinforced with cocoa pod husk. The volume proportion influence of cocoa pod husk on the mechanical attributes of the composites was tested extensively.

Further that year, Imoisili et al. [36] examined the physicochemic al attributes of the influence of volume proportion changes in the filling of epoxy resin with particles of cocoa pod husk. The water absorption test of cocoa was the interest of Imoisili et al. [37]. The second research group, Chun and workers also did comprehensive testing on the effect of filler composition as well as modifications of structures on the performance of the coc oa pod husk composites in 2016 [7]. In tw o separate public ations $[5,6]$, additional chemical treatments of the cocoa pod husk composite were made. Beyond this, torque and rheological properties of cocoa pod husk composites were examined by Chun et al. [8]. Although some other papers may have considered cocoa pod husk as reinforcement in composites, the mention papers are briefs of the papers in the area. From the survey, despite the extensive interest of researchers to use cocoa pod husk reinforc ement in composites, there is no documentation to reveal the synergic combination of cocoa pod husk and guinea fowl feathers. This remains an interesting research gap to fill.

\subsection{Summary and research gap}

In the past few years, several scholars have contributed to the development of hybrid composites based on agro-wastes for biodegradability and renew ability motivations. Composites made of bagasse and cocoa pod dusk were manufactured and tested for their properties, including thermal, mechanical, tribological and chemical treatment have been made by these researchers using various additives such 
as alkali. In all these cases, the target had mainly been experimenting with some "best guesses" on composite properties for development. But such studies have omitted optimisation by the Taguchi technique. Hence, it is essential to develop a unique approach to solve the optimisation problem for the parameters that are controlling the water absorption proc ess while integrating bagasse powder, partic ular cocoa pod husk and powdered guinea fowl feathers as composites. Interestingly, A survey of agro-based composite literature showed that extensive studies have been conducted on bagasse composites and cocoa pod husk composites. However, very few scholars have integrated these reinforcements in their particulate forms. Only a few scholars have initiated studies to hybridize bird's feathers w ith agro wastes. Such feathers have been limited to chicken feathers but no account has been reported on guinea fowl feathers to the best of the authors' knowledge. It is inferred that epoxy composites having reinforc ements as bagasse and cocoa pod husk particulates may have their performance enhanced in applications requiring toughness and tribological attributes if particulate guinea fowl feathers are added to these two reinforcements. From the literature, it may be concluded that there is scope to integrate bagasse powder, particulate cocoa pod husk and pow dered guinea fowl feathers.

\section{Methods}

In this article, the research falls into two major aspects; one requiring experimental setup and implementation and the second involving mathematical models for predictions and optimizations. Consequently, this section is developed based on the following major subsections; Experimental methods and mathematical methods. The experimental methods discuss the materials and methods, laboratory experiments and water absorption. The aspect of mathematical methods discusses the Taguchi experimentation. However, the section commences with the experimental methods.

\subsection{Experimental methods}

\subsubsection{Materials and methods}

Bagasse, a waste, was collected from wheel-barrow pushing market vendors stretching through Abule-Oja (a location close to the University of Lagos) to the Bariga market. The waste was sun-dried and later pulverized into fine particles through the use of a commercial machine. The cocoa pod husk, the second component used in this work, was obtained from a farm settlement in Aran Orin, Irepodun local government of Kwara State, Nigeria. It was ground and pulverized in the Bariga market and sieved into nanoparticles. The third pow dered component, guinea fowl feather particulates were obtained after grinding in a commercial machine. Bird merchants were approached at the Bariga market for feathers of guinea fowls, which were removed from the processed guinea fowls whose customers prefer to dispose of the feathers as waste during the purchase of the live guinea fowls.

The feathers were sun-dried for an easy grinding in the machine. Then sieves of different meshes were used but the $3 \mathrm{~mm}$ size aided the sieving. Thus, the $3 \mathrm{~mm}$ particle size was used in the experiment. The guinea fowl feather particulates were used as reinforcement to reduce the w ear rate of the composite. How ever, in filling the composite was done such that the total weight of the particulates and fillers were taken as $25 \%$ weight of the resin, which is an averagely of $60 \mathrm{~g}$ in a market plastic mould. The epoxy with harder was bought from Tony Investment Enterprises in Ojota, Lagos, Nigeria and was used as a matrix for the composite. The filler and reinforcement were taken in the proportion of the total weight of the filler and reinforcement in the stated proportions of 90:5:5, 80:10:10, 70:15:15, 60:20:20 and 50:25:25 percent by mass. This was represented in a code on the containers as $G_{i j}$, where $i$ and $j$ range from 1 to 5 . As $i$ signifies the total percentage represented as 1 is for $25 \%, 2$ for $20 \%, 3$ for $15 \%, 4$ for $10 \%$ and 5 for $5 \%$. In a like manner, $j$ represents the proportion of reinforcement $j$. while 1 is for $90 \%$, 2 is for $80 \%, 3$ is for $70 \%, 4$ is for $60 \%$ and 5 is $50 \%$ (Figure 1 and Table $1 \mathrm{a}$ ). 


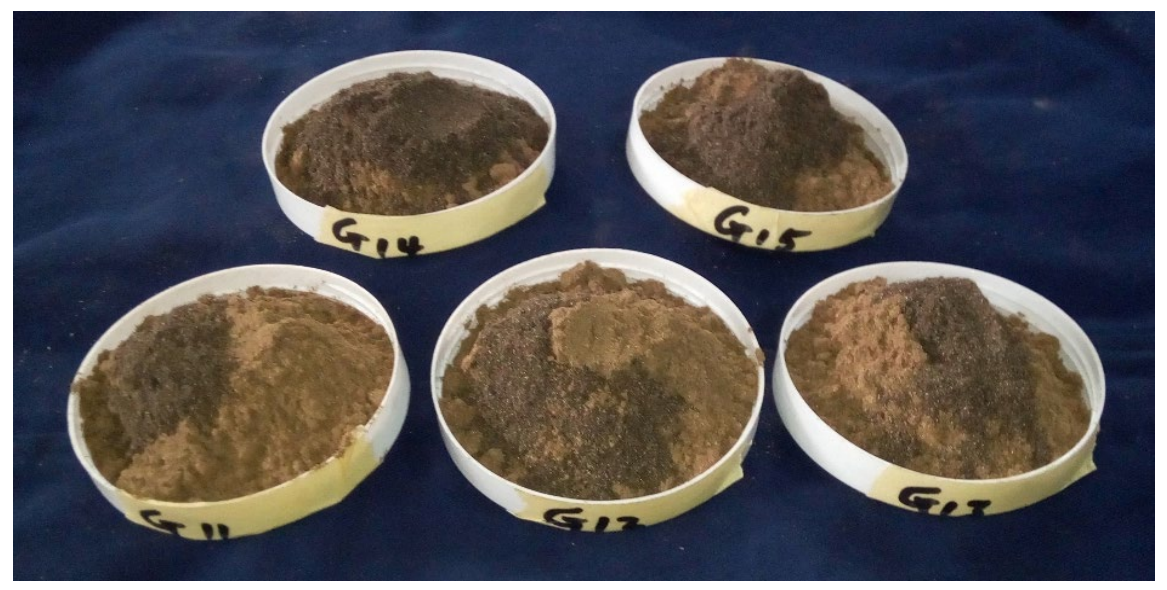

Figure 1. Samples

In this work, bagasse was used majorly as filler while cocoa pod hustle particulates were used as reinforc ement. The proportions of reinforcement used for composite fabrication is shown in Table 1a.

Table 1a. The proportion of reinforc ement for composite fabrication

\begin{tabular}{|c|c|c|c|c|c|c|c|c|c|c|}
\hline \multirow{2}{*}{$\begin{array}{l}\text { Percentage of } \\
\text { reinforcement }\end{array}$} & \multirow[b]{2}{*}{ Notation } & \multicolumn{3}{|c|}{ Filler percentage } & \multicolumn{3}{|c|}{ Filler content $(\mathrm{g})$} & \multicolumn{3}{|c|}{ \% Reinforcement overall } \\
\hline & & B & $\mathbf{H}$ & G & $\mathbf{B}$ & H & $\mathbf{G}$ & $\% B$ & $\% \mathrm{H}$ & $\% G$ \\
\hline \multirow{5}{*}{25} & $\mathrm{G}_{11}$ & 90 & 5 & 5 & 13.5 & 0.75 & 0.75 & 22.5 & 1.25 & 1.25 \\
\hline & $\overline{\mathrm{G}_{12}}$ & 80 & 10 & 10 & 12 & 1.5 & 1.5 & 20 & 2.5 & 2.5 \\
\hline & $\overline{\mathrm{G}_{13}}$ & $\overline{70}$ & 15 & 15 & $\overline{10.5}$ & 2.25 & 2.25 & 17.5 & 3.75 & $\overline{3.75}$ \\
\hline & $\mathrm{G}_{14}$ & 60 & 20 & 20 & 9 & 3 & 3 & 15 & 5 & 5 \\
\hline & $\mathrm{G}_{15}$ & 50 & 25 & 25 & 7.5 & 3.75 & 3.75 & 12.5 & 6.25 & 6.25 \\
\hline
\end{tabular}

Key:B - Bagassenanoparticles, H - cocoa pod husk nanoparticles, G- Guinea fowl feathers $3 \mathrm{~mm}$ particles

Table 1b. Properties of raw materials (reinforcements and matrix)

\begin{tabular}{|l|l|l|l|l|l|}
\hline Properties & $\begin{array}{l}\text { Epoxy resin } \\
{[\mathbf{3 8}]}\end{array}$ & $\begin{array}{l}\text { Hardener } \\
{[\mathbf{3 8}]}\end{array}$ & $\begin{array}{l}\text { Bagasse } \\
{[\mathbf{3 9}]}\end{array}$ & $\begin{array}{l}\text { Cocoa pod husk } \\
{[\mathbf{4 0 ]}}\end{array}$ & $\begin{array}{l}\text { Guinea fowl } \\
\text { Feathers [41] }\end{array}$ \\
\hline Density $(\mathrm{g} / \mathrm{cc})$ & $1.15-1.2$ & 0.968 & - & - & - \\
\hline $\begin{array}{l}\text { Viscosity at } 25^{\circ} \mathrm{C} \\
(\text { Centipoise })\end{array}$ & 815 & 74 & - & - & - \\
\hline Boiling temperature $\left({ }^{\circ} \mathrm{C}\right)$ & 180 & 207 & - & - & - \\
\hline Ignition temperature $\left({ }^{\circ} \mathrm{C}\right)$ & 390 & 240 & - & - & - \\
\hline Tensile strength $(\mathrm{MPa})$ & $68.3 \pm 1.7$ & - & - & - & - \\
\hline Moisture $(\mathrm{w} / \mathrm{w} \%)$ & - & - & 9.1 & - & $2.6-9.8$ \\
\hline Ash $(\mathrm{w} / \mathrm{w} \%)$ & - & - & 5 & $91-101$ & - \\
\hline Sugar $(\mathrm{w} / \mathrm{w} \%)$ & - & - & 1.23 & & - \\
\hline Protein $(\mathrm{w} / \mathrm{w} \%)$ & - & - & 2.65 & $59-76.6$ & - \\
\hline Acidic number(w/w\%) & - & - & 0.5 & & - \\
\hline Extractive $(\mathrm{w} / \mathrm{w} \%)$ & - & - & 0.8 & & - \\
\hline Cellulose $(\mathrm{w} / \mathrm{w} \%)$ & - & - & 42.5 & 42.5 & - \\
\hline Hemicellulose $(\mathrm{w} / \mathrm{w} \%)$ & - & - & 33.7 & $108-110$ & - \\
\hline Lignin $(\mathrm{w} / \mathrm{w} \%)$ & - & - & 23 & 146 & - \\
\hline Pectin $(\mathrm{w} / \mathrm{w} \%)$ & - & - & - & 61 & - \\
\hline Crude fiber $(\mathrm{w} / \mathrm{w} \%)$ & - & - & - & $226-325$ & - \\
\hline
\end{tabular}


Table $1 \mathrm{~b}$ (Cont'd). Properties of raw materials (reinforcements and matrix)

\begin{tabular}{|l|l|l|l|l|l|}
\hline Properties & $\begin{array}{l}\text { Epoxy resin } \\
{[\mathbf{3 8}]}\end{array}$ & $\begin{array}{l}\text { Hardener } \\
{[\mathbf{3 8}]}\end{array}$ & $\begin{array}{l}\text { Bagasse } \\
{[\mathbf{3 9}]}\end{array}$ & $\begin{array}{l}\text { Cocoa pod husk } \\
{[\mathbf{4 0 ]}}\end{array}$ & $\begin{array}{l}\text { Guinea fowl } \\
\text { Feathers [41] }\end{array}$ \\
\hline $\begin{array}{l}\text { Specific heat capacity }(\mathrm{J} / \mathrm{g} \\
\left.{ }^{\circ} \mathrm{K}\right)\end{array}$ & - & - & - & - & $0.64-0.69$ \\
\hline $\begin{array}{l}\text { Thermal conductivity } \\
\left(\mathrm{W} / \mathrm{m}^{\circ} \mathrm{K}\right)\end{array}$ & - & - & - & - & $0.25-0.73$ \\
\hline Fibre/Quill ratio & - & - & - & - & $1.4-2.7$ \\
\hline $\begin{array}{l}\text { Bulk density (fibre) } \\
\left(\mathrm{kg} / \mathrm{m}^{3}\right)\end{array}$ & - & - & - & - & $37.89-276.21$ \\
\hline Bulk density (ash) $\left(\mathrm{kg} / \mathrm{m}^{3}\right)$ & - & - & - & - & $322.93-451.88$ \\
\hline $\begin{array}{l}\text { Solid density (fibre) } \\
\left(\mathrm{kg} / \mathrm{m}^{3}\right)\end{array}$ & - & - & - & - & $258.33-276.21$ \\
\hline $\begin{array}{l}\text { Solid density (ash }) \\
\left(\mathrm{kg} / \mathrm{m}^{3}\right)\end{array}$ & - & - & - & - & $286.31-322.93$ \\
\hline
\end{tabular}

Table 1a shows the results of all the formulations used in this study. In all, five formulations were used, namely, $G_{11}, G_{12}, G_{13}, G_{14}$ and $G_{15}$. The formations were tested in water for 216 days, which is a long-term between 7 and 8 months. Aclose study of the performance of each formulation was conducted to observe the formulation that absorbs the least amount of water. Surprisingly, the formulation $\mathrm{G}_{15}$ showed the best performance. Thus, it became the focal formulation in the setting of levels with which the orthogonal array is to be determined. In this work, the smaller-the-better criterion for the choice of the signal-to-noise ratio is selected and to establish the level, this criterion was considered. Table $1 \mathrm{~b}$ shows the properties of the raw materials used for this study.

\subsubsection{Laboratory experiment}

After the curing process, the fabricated composites in their respective moulds were weighed using the Vibra electric weighing machine to obtain their initial weights. The moulds were item filled with $190 \mathrm{ml}$ of water based on the capacity of the measuring instruments. It was weighed with the composite inside to obtain the weight increase of the composite and then refilled with $190 \mathrm{ml}$ of water and weighted to obtain the corresponding increase in the weight of the composite damped in water. The average of the values (i.e. drained weight and damped). The average weight of the plastic mould was found to be $20,84 \mathrm{~g}$. By taking this from the initial weight, the actual initial weights of the composite were calculated. The obtained results were applied to Equation (1) and the graph in Figure 1 was generated.

\subsubsection{Water absorption}

The water absorption for each of the composites was calculated using Equation (1) and the value from the calculations was used to generate the graph presented in Figure 1. Equation (1) is expressed as:

$$
\% \text { of water absorbed }=\left[\left(W_{c}-W_{1}\right) / W_{i}\right] 100 \%
$$

where $W_{1}$ is the first weight recorded with the plastic mould, $W_{c}$ is the mould, $W_{i}$ is the initial weight of the composite, which is $W_{1}-W_{p}$, and $W_{p}$ is the average weight of the plastic mould. From Figure 1, composite $\mathrm{G}_{15}$ was selected for further analysis because it demonstrates the least water 
absorption among all the fabricated composites. Next, the mathematical methods are considered under the Taguchi method.

\subsection{Taguchi method}

In this article, the water absorption problem regarding the hybrid bagasse pod husk $(\mathrm{CPH})$ guinea fowl feather composite was formulated and solved as a Taguchi optimisation problem. Thus, it is essential to highly the steps adopted to solve the problem here.

Step 1: Establish the most important factors in the system, which contributes to the response(s) define the response and factor.

Step 2: $\quad$ Established level for the factors

Step 3: Determine the orthogonal array fit for the problem

Step 4: Compute the signal to noise ratios for each factor

Step 5: Aggregate the signal to noise into a response table by finding their averages

Step 6: Determine the optimal parametric setting for the problem, read from the response table established for the problem.

Step 7: $\quad$ Subject the signal to noise ratio of the Taguchi experiment to exponential smoothening a new set of optimal parametric setting.

Step 8: Carry out the experiential smoothening with 0.05 damping factor to 1 but in 0.05 intervals

Step 9: Determine the optimum parameters from the varying damping factors.

The use of the Taguchi optimisation method was motivated by the ability of the researcher to incorporate many factors into the analysis. In this work, three factors were identified and analysed, namely, the time of experiments, weight gained by drained composites and the weight gained by composites damped in $190 \mathrm{ml}$ of water. In deploying the Taguchi method to solve the water absorption parametric optimisation problem, three criteria representing the signal to noise concept is considered and the appropriate one chosen. The criteria are the MP, which is the maximum is preferred, and the NMP, the nominal is the most preferred [42]. It is reasonable to state that the smaller the water absorbed by composite material, the better its mechanical properties. Consequently, the choic ef the SP was made as a criterion representing the signal to noise ratio that was used in this study. The L25 orthogonal array with three factors and five levels was used. The factors, time of the experiment, weight gained by the drained composite and the weight gained by composite and the weight gained by composite damped in $190 \mathrm{ml}$ of water conveniently represented as symbol A, B and C, respectively. The choice the smaller the preferred criterion is shown in Equation (2).

$$
\frac{S}{N}=-10 \log 10\left(\frac{1}{k} \sum_{i=1}^{k} B_{i}^{2}\right)
$$

Here, $B_{i}$ signifies the choice of the smaller is the preferred property, the $\mathrm{S} / \mathrm{N}$ is the signal-to-noise ratio and $\mathrm{k}$ is the experimental frequency [43]. Often, the Microsoft Excel software spreadsheet may be useful to compute the property mentioned above, and the results are presented afterwards. 


\section{Results}

\subsection{General}

In this section, first, the data regarding the increase in composites' weights as a result of w ater absorption are gathered, Table 2. Furthermore, Table 3 summarises the initial and final weights of the composites.

Table 2. Increase in composites' weights as a result of water absorption

\begin{tabular}{|c|c|c|c|c|c|c|c|c|c|c|}
\hline \multirow[b]{2}{*}{ Time(days) } & \multicolumn{5}{|c|}{ Weightgainedby drained composites (g) } & \multicolumn{5}{|c|}{$\begin{array}{l}\text { Weight gained by composites taken with } 190 \mathrm{ml} \\
\text { of water (g) }\end{array}$} \\
\hline & $\mathrm{G}_{11}$ & $\mathrm{G}_{12}$ & $\mathrm{G}_{13}$ & $\mathrm{G}_{14}$ & $\mathrm{G}_{15}$ & $\mathrm{G}_{11}$ & $\mathrm{G}_{12}$ & $\mathrm{G}_{13}$ & $\mathrm{G}_{14}$ & $\mathrm{G}_{15}$ \\
\hline 4 & 2.78 & 5.70 & 3.33 & 4.03 & 4.22 & 1.59 & 6.29 & 3.68 & 5.21 & 4.34 \\
\hline 11 & 4.96 & 6.80 & 5.87 & 5.69 & 5.78 & 3.18 & 2.81 & 4.47 & 1.44 & 6.6 \\
\hline 18 & 10.84 & 7.76 & 9.06 & 7.24 & 8.56 & 6.18 & 5.18 & 7.47 & 7.21 & 5.27 \\
\hline 25 & 14.11 & 8.81 & 11.05 & 10.55 & 10.62 & 13.84 & 5.12 & 7.24 & 8.92 & 8.47 \\
\hline 32 & 16.28 & 11.27 & 12.57 & 12.86 & 11.97 & 16.14 & 10.29 & 12.58 & 14.37 & 10.38 \\
\hline 39 & 9.02 & 11.44 & 8.56 & 12.00 & 10.94 & 8.15 & 12.49 & 7.76 & 13.21 & 12.64 \\
\hline 46 & 10.02 & 12.33 & 9.40 & 14.50 & 13.02 & 11.37 & 11.58 & 8.83 & 15.06 & 4.4 \\
\hline 53 & 9.39 & 13.39 & 10.6 & 13.51 & 12.63 & 8.65 & 11.96 & 11.00 & 12.28 & 11.75 \\
\hline 63 & 10.07 & 13.51 & 11.23 & 13.98 & 13.19 & 11.45 & 11.91 & 11.21 & 14.49 & 13.93 \\
\hline 67 & 11.44 & 13.86 & 8.65 & 26.42 & 12.81 & 9.94 & 11.70 & 5.970 & 16.35 & 11.7 \\
\hline 74 & 12.14 & 14.59 & 9.80 & 19.03 & 9.90 & 10.66 & 12.51 & 7.67 & 17.66 & 7.96 \\
\hline 81 & 9.62 & 15.99 & 10.12 & 11.99 & 11.51 & 6.47 & 23.23 & 8.41 & 10.28 & 10.31 \\
\hline 91 & 7.93 & 14.28 & 9.98 & 12.38 & 10.46 & 4.52 & 8.29 & 7.06 & 8.33 & 6.93 \\
\hline 98 & 9.14 & 16.11 & 10.75 & 14.87 & 9.61 & 8.95 & 12.64 & 10.65 & 14.36 & 8.47 \\
\hline 102 & 9.02 & 15.38 & 10.76 & 12.47 & 8.35 & 8.89 & 13.79 & 11.29 & 11.51 & 9.73 \\
\hline 109 & 9.40 & 15.07 & 10.85 & 12.83 & 8.59 & 8.79 & 12.07 & 10.80 & 12.17 & 7.32 \\
\hline 129 & 10.69 & 14.97 & 12.74 & 15.40 & 10.53 & 9.34 & 14.08 & 10.88 & 16.3 & 8.61 \\
\hline 136 & 11.82 & 15.82 & 12.99 & 16.61 & 10.80 & 14.63 & 13.98 & 11.62 & 17.76 & 10.24 \\
\hline 144 & 10.74 & 14.70 & 13.40 & 17.72 & 10.67 & 7.08 & 9.46 & 9.88 & 16.98 & 7.69 \\
\hline 151 & 11.50 & 15.01 & 13.07 & 17.74 & 11.60 & 9.40 & 12.28 & 10.40 & 17.17 & 11.38 \\
\hline 158 & 12.30 & 16.60 & 15.59 & 17.16 & 12.30 & 17.11 & 5.98 & -5.02 & 9.30 & 1.84 \\
\hline 165 & 13.05 & 16.59 & 15.16 & 17.95 & 12.70 & 15.24 & 8.36 & 19.01 & 20.42 & 11.45 \\
\hline 172 & 12.72 & 16.49 & 15.20 & 17.36 & 12.72 & 10.83 & 18.30 & 11.57 & 16.81 & 11.38 \\
\hline 182 & 12.99 & 17.03 & 16.31 & 19.24 & 12.40 & -4.75 & -7.75 & 4.90 & 8.61 & -7.44 \\
\hline 216 & 14.25 & 16.62 & 19.73 & 24.24 & 12.29 & 14.68 & 17.66 & 19.23 & 28.34 & 15.2 \\
\hline
\end{tabular}

Table 3. Initial and final weights of the composites

\begin{tabular}{|c|r|r|}
\hline Notation & $\begin{array}{l}\text { Initial } \\
\text { Weight }(\mathbf{g})\end{array}$ & $\begin{array}{l}\text { Final } \\
\text { weight } \mathbf{( g )}\end{array}$ \\
\hline $\mathrm{G}_{11}$ & 90.12 & 104.37 \\
\hline $\mathrm{G}_{12}$ & 69.72 & 86.34 \\
\hline $\mathrm{G}_{13}$ & 83.04 & 102.77 \\
\hline $\mathrm{G}_{14}$ & 91.48 & 115.72 \\
\hline $\mathrm{G}_{15}$ & 107.86 & 120.15 \\
\hline
\end{tabular}


Following this, the authors established the factors and levels, Table 4. The factors were decided upon based on an exhaustive discussion of the researchers with experts in the composites industry, and researcher. It was also coupled with an extensive literature search. The outcome is the decision to use the following important parameters ass representatives of the water absorption process for the hybrid bagasse particles (B), particulates cocoa pod husk (CPH) and pow dered guinea fowl feathers (GFF) epoxy composite: time of experiment weight gained by drained composites and weight gained by damped composites, Table 4.

Table 4. Factors considered and their respective levels

\begin{tabular}{|c|l|c|c|c|c|c|}
\hline S/No & \multicolumn{1}{|c|}{ Factors } & \multicolumn{5}{|c|}{ Levels } \\
\cline { 3 - 7 } & & 1 & 2 & 3 & 4 & 5 \\
\hline 1 & A: Time of experiment (days) & 4 & 39 & 74 & 109 & 158 \\
\hline 2 & $\begin{array}{l}\text { B: weight gained by drained } \\
\text { composites (g) }\end{array}$ & 4.22 & 10.94 & 8.35 & 8.59 & 12.29 \\
\hline 3 & $\begin{array}{l}\text { C: } \text { weight gained by composites } \\
\text { damped in 190 ml of water(g) }\end{array}$ & 4.34 & 4.40 & 6.93 & 7.32 & -7.44 \\
\hline
\end{tabular}

Consider Table 4 that consists of factors and levels, the question is how were the levels determined for the present study? Take the first factor, time, for instance, all the 216 days' data were collected twenty-five times. So, a convenient dividing scale is five. Thus, data concerning the five groups were considered. For the time as a factor, periods $4,11,18,25$ and 32 were grouped and based on the smallerthe-better criterion, the value, 4, was picked as the least. For the next set, 39, 46, 53, 63 and 67, the value 39 was chosen. Likewise, for 74, 81, 91, 98 and 102, the value 74 was chosen. For the set 109, 129, 136, 144 and 151, the value 109 was chosen, and lastly, 158 w as chosen from the group containing numbers $158,165,172,182$ and 216 . The corresponding group values under $\mathrm{G}_{11}$ for the second factor were tracked. Corresponding to 4, 11, 18, 25 and 32 under time are 4.22, 5.78, 8.56 and 10.62 for $\mathrm{G}_{11}$ under the weight gained by drained composites. Out of these values, the minimum is 4.22 and hence chosen to represent the first level under the factor, B. Similarly, the corresponding values to time of 39, 46, 53, 63 and 67 are 10.94, 13.02, 12.63, 13.19 and 12.81. Out of these values under $\mathrm{G}_{15}$, the minimum is 10.94 and therefore chosen. This is the value for level 2 under factor $\mathrm{B}$. The same procedure is followed to fill the table with level values for the rest of the "B" factor and "C" factor.

Table 5. L25 orthogonal array experiment design

\begin{tabular}{cccccccc}
\hline $\begin{array}{c}\text { Experimental } \\
\text { Trial }\end{array}$ & A & B & C & $\begin{array}{c}\text { Experimental } \\
\text { trial }\end{array}$ & A & B & C \\
\hline 1 & 1 & 1 & 1 & 14 & 3 & 4 & 1 \\
2 & 1 & 2 & 2 & 15 & 3 & 5 & 2 \\
3 & 1 & 3 & 3 & 16 & 4 & 1 & 4 \\
4 & 1 & 4 & 4 & 17 & 4 & 2 & 5 \\
5 & 1 & 5 & 5 & 18 & 4 & 3 & 1 \\
6 & 2 & 1 & 2 & 19 & 4 & 4 & 2 \\
7 & 2 & 2 & 3 & 20 & 4 & 5 & 3 \\
8 & 2 & 3 & 4 & 21 & 5 & 1 & 5 \\
9 & 2 & 4 & 5 & 22 & 5 & 2 & 1 \\
10 & 2 & 5 & 1 & 23 & 5 & 3 & 2 \\
11 & 3 & 1 & 3 & 24 & 5 & 4 & 3 \\
12 & 3 & 2 & 4 & 25 & 5 & 5 & 4 \\
13 & 3 & 3 & 5 & & & & \\
\hline
\end{tabular}


Based on the choice of three factors and five levels, the most appropriate orthogonal is L25 and therefore chosen, Table 5. In all, twenty-five experimental trials may be generated through the orthogonal array of the Taguchi scheme. The numbers indicated are the levels that may be read from Table 4. For instance, consider the experimental trial 1, under A, B and C, respectively values shown are 1,1 , and 1 . It means that the actual value in Table 2 for level 1 under factor $\mathrm{A}$, which is 4 needs to be used to replace 1 in a new table created. For factor B, the value of 4.22 should replace 1 , while the value of 4.34 should replace 1. By following this convention, a new Table 6 contains replacements of values for Table 5 as follows.

Table 6. Signal-to-noise ratio computation for the parameters

\begin{tabular}{|c|c|c|c|c|c|c|c|c|r|}
\hline S/No & $\mathbf{A}$ & $\mathbf{B}$ & $\mathbf{C}$ & \multicolumn{1}{|c|}{ S/N ratio } & S/No & $\mathbf{A}$ & $\mathbf{B}$ & $\mathbf{C}$ & S/N ratio \\
\hline 1 & 4 & 4.22 & 4.34 & -3.23409 & 14 & 74 & 8.59 & 4.34 & -23.4781 \\
\hline 2 & 4 & 10.94 & 4.4 & -7.92514 & 15 & 74 & 12.29 & 4.4 & -23.5383 \\
\hline 3 & 4 & 8.35 & 6.93 & -7.28345 & 16 & 109 & 4.22 & 7.32 & -26.7951 \\
\hline 4 & 4 & 8.59 & 7.32 & -7.5852 & 17 & 109 & 10.94 & -7.44 & -26.8326 \\
\hline 5 & 4 & 12.29 & -7.44 & -9.4919 & 18 & 109 & 8.35 & 4.34 & -26.8014 \\
\hline 6 & 39 & 4.22 & 4.4 & -17.9467 & 19 & 109 & 8.59 & 4.4 & -26.803 \\
\hline 7 & 39 & 10.94 & 6.93 & -18.2961 & 20 & 109 & 12.29 & 6.93 & -26.8413 \\
\hline 8 & 39 & 8.35 & 7.32 & -18.1804 & 21 & 158 & 4.22 & -7.44 & -30.0065 \\
\hline
\end{tabular}

Table 6 (Cont'd). Signal-to-noise ratio computation for the parameters

\begin{tabular}{|c|c|c|c|c|c|c|c|c|c|}
\hline S/No & $\mathbf{A}$ & $\mathbf{B}$ & $\mathbf{C}$ & S/N ratio & S/No & $\mathbf{A}$ & $\mathbf{B}$ & $\mathbf{C}$ & S/N ratio \\
\hline 9 & 39 & 8.59 & -7.44 & -18.1958 & 22 & 158 & 10.94 & 4.34 & -30.0178 \\
\hline 10 & 39 & 12.29 & 4.34 & -18.3017 & 23 & 158 & 8.35 & 4.4 & -30.0092 \\
\hline 11 & 74 & 4.22 & 6.93 & -23.4571 & 24 & 158 & 8.59 & 6.93 & -30.0149 \\
\hline 12 & 74 & 10.94 & 7.32 & -23.5405 & 25 & 158 & 12.29 & 7.32 & -30.0292 \\
\hline 13 & 74 & 8.35 & -7.44 & -23.5033 & & & & & \\
\hline
\end{tabular}

In Table 6, the last column is the signal-to-noise ratio, which is computed based on Equation (2) mentioned previously. A simple spreadsheet is prepared where -10, and log 10 are multiplied with the factor in the bracket. The computation is made for each experimental trial at once where $\mathrm{K}$ is taken as 3 and the values for each factor is squared and added together. Eventually, a representative value for Equation (2) will be obtained.

Table 7. Analysis of variance among the three factors

Summary

\begin{tabular}{|c|c|c|c|c|c|c|}
\hline Groups & Count & Sum & Average & Variance & & \\
\hline $\mathrm{A}$ & 25 & 1920 & 76.8 & 2993.083 & & \\
\hline B & 25 & 221.95 & 8.878 & 7.906725 & & \\
\hline $\mathrm{C}$ & 25 & 77.75 & 3.11 & 30.5825 & & \\
\hline \multicolumn{7}{|l|}{ ANOVA } \\
\hline Source of Variation & $S S$ & $D f$ & $M S$ & $F$ & $P$-value & Fcrit \\
\hline Between Groups & 83974.03 & 2 & 41987.02 & 41.54974 & $1 \mathrm{E}-12$ & 3.123907 \\
\hline Within Groups & 72757.74 & 72 & 1010.524 & & & \\
\hline Total & 156731.8 & 74 & & & & \\
\hline
\end{tabular}


The ANOVA tables results (Table 7) are useful to establish whether the specified factors are signific antly associated with the response data or not. It also aids to establish the comparative importance of each factor in the model. Based on this declaration, factor A, which is the time of experiments, expressed in days, shows the biggest sum of squares of 1920 and the greatest impact on the water absorption parametric optimisation using the Taguchi scheme. The second rank in the sum of squares is assigned to factor $\mathrm{B}$, which is the weight gained by drained composites, with a sum of square value of 221.95. It means that some impacts (roughly $11.60 \%$ in relative strength to factor $\mathrm{A}$ ) are exercised by factor B on the Taguchi model. How ever, the least impact on the Taguchi model is exercised by factor $\mathrm{C}$ with a sum of the square of 77.75 , which is as low as $4.05 \%$ in the strength of factor A.

Regression statistics were conducted on the data generated from the experiments, which were transformed by the orthogonal array and the signal to noise ratio computation (Table 8). In using the regression statistics, the confidence level was set at $95 \%$, the input response variable was the signal to noise ratios for the twenty-five experimental trials while the input parameters were the three factors, $A$, $\mathrm{B}$ and $\mathrm{C}$. Usually, the criterion for acceptance is when the adjusted $R^{2}$ is greater than $65 \%$ however, in this case, the adjusted $R^{2}$ was $86.50 \%$, which surpasses the $65 \%$ benchmark. It shows us that the correlation between the signal to noise ratios and the factors $\mathrm{A}, \mathrm{B}$ and $\mathrm{C}$ is reliable. Besides, it reveals that by $86.50 \%$ with the addition of the factors $\mathrm{A}, \mathrm{B}$ and $\mathrm{C}$, the confidence level of $95 \%$ is determined. Also, the p-values from the regression analysis help to understand whether any or all the factors A, B and $\mathrm{C}$ are significantly associated with the response data and the comparative importance of each factor in the regression model. Usually, a $p$-value of 3.43E-11 is significant, others are not significant.

Table 8. Regression statistics

ANOVA

\begin{tabular}{|c|c|c|c|c|c|c|c|c|}
\hline & \multirow[b]{2}{*}{$D f$} & \multicolumn{7}{|c|}{ Significance } \\
\hline & & $S S$ & $M S$ & $F$ & $F$ & & & \\
\hline Regression & 3 & 1440.384 & 480.1281 & 52.2776 & $6.48 \mathrm{E}-10$ & & & \\
\hline Residual & 21 & 192.8683 & 9.184203 & & & & & \\
\hline \multirow[t]{3}{*}{ Total } & 24 & 1633.253 & & & & & & \\
\hline & & Standard & & & & Upper & Lower & Upper \\
\hline & Coefficients & Error & t Stat & P-value & Lower 95\% & $95 \%$ & $95.0 \%$ & $95.0 \%$ \\
\hline Intercept & -8.9725 & 2.248829 & -3.98986 & 0.000666 & -13.6492 & -4.29581 & -13.6492 & -4.29581 \\
\hline $\mathrm{A}$ & -0.14132 & 0.011307 & -12.4985 & $3.43 \mathrm{E}-11$ & -0.16484 & -0.11781 & -0.16484 & -0.11781 \\
\hline B & -0.1587 & 0.219997 & -0.72137 & 0.478639 & -0.61621 & 0.29881 & -0.61621 & 0.29881 \\
\hline $\mathrm{C}$ & 0.035582 & 0.111861 & 0.31809 & 0.753558 & -0.19705 & 0.268209 & -0.19705 & 0.268209 \\
\hline
\end{tabular}

Furthermore, the response table (Table 9) needs to be evaluated, which is the aggregation of the average of the signal-to-noise ratios of the experimental trials. The question is how do we transform Table 6, containing the signal-to-noise ratios into a response table, Table 9? The procedure is as follows. Please notice that the response table has three factors and five levels. So, the computation starts for the first factor $\mathrm{A}$, and level 1. To obtain the values the signal-to-noise ratio table is referred to under the column for factor A, all the representatives by " 1 " are noted. But each of these representations has a corresponding signal-to-noise ratio computed for it. So, the signal-to-noise ratios are summed up and average while the value is transferred to the cell containing level 1 and factor $\mathrm{A}$ in the response table. The procedure followed to fill the response table is similar to the one followed to obtain value for factor A. 
Table 9. Response table

\begin{tabular}{|c|c|c|c|}
\hline Levels & A & B & C \\
\hline 1 & -7.10396 & -20.2879 & -20.3666 \\
\hline 2 & -16.1858 & -17.7687 & -21.2445 \\
\hline 3 & -22.3387 & -21.1556 & -21.1786 \\
\hline 4 & -26.8147 & -21.2154 & $\mathbf{- 2 1 . 2 2 6 1 ^ { * }}$ \\
\hline 5 & $\mathbf{- 2 9 . 3 0 6 6}^{*}$ & $\mathbf{- 2 1 . 6 4 0 5}$ & -18.005 \\
\hline
\end{tabular}

After obtaining the response table, the issue is to obtain the optimal parametric setting from the response table. Along the column, the least value is chosen and asterisked as the optimal for that level. The procedure is followed until all the levels have associated optimal points. This is then read as a whole by taking into consideration each outcome at the level. The response table (Table 9) shows the optimal parametric setting of $\mathrm{A}_{5} \mathrm{~B}_{5} \mathrm{C}_{4}$, indic ating 158 days, $12.29 \mathrm{~g}$ of drained composite and $7.32 \mathrm{~g}$ of the damped composite.

A significant novelty claimed in this paper is the introduction of the experimental smoothing function to and prediction for planning purposes. But this is used on the signal-to-noise data generated in the experimental trials table. To apply the exponential smoothing a smoothening constant is adopted, which ranges from 0.05 to 1 in steps of 0.05 . So, at the initial level, a smoothening factor of 0.05 is taken. Furthermore, the proc edure to evaluate the response table is follow ed and a revised response table, based on the exponential smoothing values is produced, Table 10.

Table 10. Revised (exponential smoothening based) signal to noise response table for 0.1 damping factor

\begin{tabular}{|c|r|r|r|}
\hline Levels & \multicolumn{1}{c|}{ A } & \multicolumn{1}{c|}{ B } & \multicolumn{1}{c|}{ C } \\
\hline 1 & -6.3869 & -19.4898 & -19.6362 \\
\hline 2 & -16.1858 & -19.883 & -15.4664 \\
\hline 3 & -22.3387 & -21.1785 & -16.6064 \\
\hline 4 & -26.0803 & -19.7471 & -16.9938 \\
\hline 5 & $\mathbf{- 2 9 . 3 0 6 6}$ & $\mathbf{- 2 1 . 2 0 9 6}$ & $\mathbf{- 2 0 . 5 0 4 7 ^ { * }}$ \\
\hline
\end{tabular}

Another version of the signal-to-noise ratios with the twenty-five experimental trials is shown in Table 10. However, extensive testing of the model is made while the exponential smoothening constant varies from 0.05 to 1 . The summary of results is shown in Table 11 .

The optimum parameters were determined from the response table (Table 9) and compared with the predicted optimal parametric setting (Table 10) based on the exponential smoothening forecasting model with the damping factor of 0.1 . The aim is to investigate the influence of forecasting model performance on the optimal parametric setting of the composite. The finding shows a change in the optimal parametric setting from $\mathrm{A}_{5} \mathrm{~B}_{5} \mathrm{C}_{4}$ (w ithout forec asting model) to $\mathrm{A}_{5} \mathrm{~B}_{5} \mathrm{C}_{5}$ (w ith forec asting model). The interpretation of the change is that the optimal parametric setting without the forecasting model was 158 days of experiments and $12.29 \mathrm{~g}$ of weight gained by drained composites as well as $7.32 \mathrm{~g}$ of weight gained by composite. How ever, the optimal parametric setting with the forecasting model was 158 days of experiments and $12.29 \mathrm{~g}$ of weight gained by drained composites as well as $-7.44 \mathrm{~g}$ of weight gained by composites. This implies that the experiential forecasting model enhanced the performance of the composite as it was noticed that the $-7.44 \mathrm{~g}$ of weight gained by composites is a reduction in weight of the composite by $7.44 \mathrm{~g}$. 
Table 11. Optimum parameters derived from varying the damping factor

\begin{tabular}{|c|c|c|c|c|c|}
\hline S/No & $\begin{array}{c}\text { Damping } \\
\text { Factor }\end{array}$ & $\begin{array}{c}\text { Optimum } \\
\text { parametric } \\
\text { setting }\end{array}$ & S/No & $\begin{array}{c}\text { Damping } \\
\text { Factor }\end{array}$ & $\begin{array}{c}\text { Optimum } \\
\text { parametric setting }\end{array}$ \\
\hline 1 & 0.05 & $\mathrm{~A}_{5}, \mathrm{~B}_{3}, \mathrm{C}_{1}$ & 11 & 0.55 & $\mathrm{~A}_{5}, \mathrm{~B}_{5}, \mathrm{C}_{5}$ \\
\hline 2 & 0.10 & $\mathrm{~A}_{5}, \mathrm{~B}_{5}, \mathrm{C}_{5}$ & 12 & 0.60 & $\mathrm{~A}_{5}, \mathrm{~B}_{5}, \mathrm{C}_{5}$ \\
\hline 3 & 0.15 & $\mathrm{~A}_{5}, \mathrm{~B}_{5}, \mathrm{C}_{1}$ & 13 & 0.65 & $\mathrm{~A}_{5}, \mathrm{~B}_{5}, \mathrm{C}_{5}$ \\
\hline 4 & 0.20 & $\mathrm{~A}_{5}, \mathrm{~B}_{5}, \mathrm{C}_{5}$ & 14 & 0.70 & $\mathrm{~A}_{5}, \mathrm{~B}_{5}, \mathrm{C}_{5}$ \\
\hline 5 & 0.25 & $\mathrm{~A}_{2}, \mathrm{~B}_{2}, \mathrm{C}_{1}$ & 15 & 0.75 & $\mathrm{~A}_{5}, \mathrm{~B}_{5}, \mathrm{C}_{5}$ \\
\hline 6 & 0.30 & $\mathrm{~A}_{5}, \mathrm{~B}_{5}, \mathrm{C}_{1}$ & 16 & 0.80 & $\mathrm{~A}_{5}, \mathrm{~B}_{5}, \mathrm{C}_{1}$ \\
\hline 7 & 0.35 & $\mathrm{~A}_{5}, \mathrm{~B}_{5}, \mathrm{C}_{5}$ & 17 & 0.85 & $\mathrm{~A}_{5}, \mathrm{~B}_{5}, \mathrm{C}_{1}$ \\
\hline 8 & 0.40 & $\mathrm{~A}_{5}, \mathrm{~B}_{5}, \mathrm{C}_{5}$ & 18 & 0.90 & $\mathrm{~A}_{5}, \mathrm{~B}_{5}, \mathrm{C}_{1}$ \\
\hline 9 & 0.45 & $\mathrm{~A}_{5}, \mathrm{~B}_{5}, \mathrm{C}_{1}$ & 19 & 0.95 & $\mathrm{~A}_{5}, \mathrm{~B}_{5}, \mathrm{C}_{1}$ \\
\hline 10 & 0.50 & $\mathrm{~A}_{5}, \mathrm{~B}_{5}, \mathrm{C}_{5}$ & 20 & 1.00 & $\mathrm{~A}_{5}, \mathrm{~B}_{5}, \mathrm{C}_{5}$ \\
\hline
\end{tabular}

The forecasting model is said to be better than the model without the forecasting content for the developed composite based on a damping factor of 0.1 . Furthermore, by looking very closely at the actual averages produced by the optimal parametric setting (with forecasting model) and the optimal parametric setting (without forecasting model) it was found that the earlier produced the same value of $\mathrm{A}_{5}(-29.3066)$ as the latter. How ever, there is a reduction of $1.99 \%$ in value of the without forecasting model ( $\mathrm{B}_{5}$ is 21.6405 without and $\mathrm{B}_{5}$ is 21.2096 with the forecasting model). Similarly, a reduction of $3.40 \%$ in value of the without forecasting model $\left(\mathrm{C}_{4}\right.$ is 21.6405 without and $\mathrm{C}_{5}$ is -20.5047 with the forecasting model). The optimal parametric setting for the damping factors ranging from 0.05 to $1.00 \mathrm{in}$ steps of 0.05 was obtained (Table 11). Compared with the optimal parametric setting without the forecasting model, it was noted that the optimal parametric setting $\left(\mathrm{A}_{5} \mathrm{~B}_{5} \mathrm{C}_{4}\right)$ changed to other settings. But in all the twenty cases, the following observations were made. First, the A component maintained $\mathrm{A}_{5}$ for 19 out of the 20 cases, the $\mathrm{B}$ component maintained the initial $\mathrm{B}_{5}$ nomenclature for 18 out of the tw enty cases while the $\mathrm{C}$ component with the nomenclature $\mathrm{C}_{4}$ had none of the damping factors repeating the same nomenclature $\mathrm{C}_{4}$ in its results. The result summarises that there is wide variability in the results given by the model containing the forecasting model. Table 12 contains the data on the comparison of experimental data and exponential smoothening based data.

Table 12. Revised (experimental data-exponential smoothening based data) S/N Ratio response Table

\begin{tabular}{|c|c|c|c|c|c|c|c|c|c|}
\hline S/No & Measured & $\begin{array}{c}\text { Exponential } \\
\text { smoothening }\end{array}$ & Difference & $\begin{array}{c}\% \\
\text { Error }\end{array}$ & S/No & Measured & $\begin{array}{c}\text { Exponential } \\
\text { smoothening }\end{array}$ & Difference & $\begin{array}{c}\% \\
\text { Error }\end{array}$ \\
\hline 1 & -3.23409 & \#N/A & \#N/A & & 14 & -23.4781 & -23.501 & 0.022957 & -0.098 \\
\hline 2 & -7.92514 & -3.23409 & -4.69105 & 59.192 & 15 & -23.5383 & -23.480 & -0.05795 & 0.246 \\
\hline 3 & -7.28345 & -7.45603 & 0.17258 & -2.369 & 16 & -26.7951 & -23.533 & -3.26262 & 12.176 \\
\hline 4 & -7.5852 & -7.30071 & -0.28449 & 3.751 & 17 & -26.8326 & -26.469 & -0.36376 & 1.356 \\
\hline 5 & -9.4919 & -7.55675 & -1.93515 & 20.387 & 18 & -26.8014 & -26.796 & -0.00511 & 0.019 \\
\hline 6 & -17.9467 & -9.29839 & -8.64836 & 48.189 & 19 & -26.803 & -26.801 & -0.00218 & 0.008 \\
\hline 7 & -18.2961 & -17.0819 & -1.21424 & 6.637 & 20 & -26.8413 & -26.803 & -0.03847 & 0.143 \\
\hline 8 & -18.1804 & -18.1747 & -0.0057 & 0.032 & 21 & -30.0065 & -26.837 & -3.169 & 10.561 \\
\hline 9 & -18.1958 & -18.1799 & -0.01596 & 0.0877 & 22 & -30.0178 & -29.690 & -0.32822 & 1.093 \\
\hline 10 & -18.3017 & -18.1942 & -0.10751 & 0.587 & 23 & -30.0092 & -29.985 & -0.02426 & 0.081 \\
\hline 11 & -23.4571 & -18.291 & -5.16616 & 22.024 & 24 & -30.0149 & -30.007 & -0.0081 & 0.027 \\
\hline 12 & -23.5405 & -22.9405 & -0.6 & 2.549 & 25 & -30.0292 & -30.014 & -0.01512 & 0.050 \\
\hline 13 & -23.5033 & -23.4805 & -0.02279 & 0.097 & & & & & \\
\hline
\end{tabular}




\subsection{Summary of findings}

Regarding the period of water experiments, to date, within the limits of the literature studied, the current paper is the only long term experimental analyses is carried out in the literature. The current study was carried out for 216 days, thereby more reliable than two other previous studies, including Imoisili et al. [37] (i.e. 2 hours) and Ayanladun and Oke [15] (i.e. 70 days) in essence, studies have carried out for short period [37], middle-term period [15] while this is the first time, to the authors' knowledge that water experiments have been conducted for combined bagasse, Guinea fowl feathers and cocoa pod reinforced epoxy composites.

Interestingly, Imoisili et al. [37] and Ayanladun and Oke [15] had their studies limited to cocoa pod husk epoxy composite whereas the present work expanded the frontier of knowledge to cover the additional reinforcements of bagasse and guinea fowl feathers of particular interest to the composite developer, and this is the first time introduction of guinea fowl feathers in particulate form to the epoxy resin as an epoxy composite in water absorption experiments. Furthermore, from Figure 1 of Imoisili et al. [37], which ac counted for changes in water absorption of cocoa pod husk composites, the maximum time of the experiment was 2 hours. The experiments w ere carried out in 10 minutes interval. This means that the experiment was conducted in a very short period. This did not give an account of the long term behaviour of composites in a water environment. Besides, Ayanladun and Oke [15] observed the experimental period of 70 days, which gives an account of a middle-range period of analysis of composite behaviour in a water environment.

Five composite formulations were made, including $\mathrm{G}_{11}, \mathrm{G}_{12}, \mathrm{G}_{13}, \mathrm{G}_{14}$, and $\mathrm{G}_{15}$ and tested in water environments (Tables 2). These data consist of two groups.the first concerns the weight gained by drained composite while the second comprises of weight gained by composite taken with $190 \mathrm{ml}$ of water in each experiment. While the graph of these behaviours shows the same pattern of information as in Table 2, it is not included in this work but interpreted for further analysis. From the graph, it was discovered that the composites with the minimum values of water absorption are the composite labelled as $\mathrm{G}_{15}$.

This means that it is the one that shows more of the least values of water absorption on each of the experiments recorded. This was then chosen as the best formulation in the formulated composite. Thus, the data for this formulation was used for Taguchi experiments. Compared with Imoisili et al. [37], the authors presented four formulations, labelled as 5\%, 10\%, 20\% and 30\% of which the best in water absorption was the composite labelled as 5\%. Weighted against Imoisili et al. [37], this work contains more numbers of particulates. While Imoisili et al. [37] was restricted to only a particulate reinforcement, which is cocoa pod husk, the present work has three particulates embedded as reinforcements, namely bagasse, guinea fowl feathers and cocoa pod husk. This makes the current work more comprehensive and reliable. The current work was able to utilize more quantity of reinforcement thereby bringing economic advantage as more reinforcements of different qualities are accommodated for better performance [44].

\subsection{Contributions}

This article contributes to knowledge on agro-based composite development in many ways. It highlights the use of guinea fowl feather particulate to reinforce composite as a hybrid for the first time in literature for the water absorption process. The synergic influence of reinforcement namely bagasse particles, cocoa pod husk powders and guinea fowl feather powder to enhance the properties of the composite, including mechanical and tribological is demonstrated for the first time in water absorption experiments. It establishes water absorption process parameters for the hybrid bagasse powder, particulate cocoa pod husk and powdered guinea fowl feather epoxy composite, which were previously unclear in the literature. This aids enhanced comprehension of the optimisation parameters by the researcher. A new mechanism for prediction, based on exponential smoothing with various damping coefficients was introduced to enhance the predictive performance of the signal to noise ratio as an input 
to the response table, producing a revised response table through which simulations of the signal to noise ratios could be made on "what if "basis for planning proposes.

\section{Conclusions}

The optimal determination of water absorption process parameters for a hybrid composite of consisting bagasse, cocoa pod husk and guinea fowl feathers as reinforcements and epoxy resin as the matrix is an unresolved composite development question. The present practice involves the evaluation of process parameters from composite when only bagasse reinforcement is used or when only cocoa pod husk is engaged as the reinforcement. However, there is no study, which has evaluated composites wherein the guinea fowl feathers were included in the composite development either as an individual reinforcement in epoxy resin matrix or as a component in the reinforcement with bagasse and cocoa pod husk.

Thus, there is no significant evidence that the composite developer could rely upon to plate to validate the workability of combining bagasse, cocoa pod husk and guinea fowl feathers in epoxy resin as composites to data. Although our study is experimental and excludes tests of composites in distilled w ater, saltw ater and sub-zero temperatures, the data suggests the combined bagasse, cocoa pod husk and guinea fowl feather epoxy composites as an acceptable option for high structural integrity in water solutions. Notwithstanding, there remains a need for more extensive enquiry in the area.

\section{References}

[1] Castro, A. M., Ribeiro, M. C. S., Santos, J., Meixedo, J. P., Silva, F. J., Fiúza, A. \& Alvim, M. R. (2013). Sustainable waste recycling solution for the glass fibre reinforced polymer composite materials $\begin{array}{llll}\text { industry. Construction } \quad \text { and } & \text { Building }\end{array}$ https://doi.org/10.1016/j.conbuildmat.2013.03.092

[2] Pillain, B., Lefeuvre, A., Garnier, S., Cadene, A. L., \& Jacquemin, L. (2020). Sustainability engineering assessment research for recycling composites with high value: Stakeholders' views. Sustainable Development, 28(1), 197-207.. https://doi.org/10.1002/sd.1986

[3] BansalG. and Singh V.K. (2016). Review on chicken feather fibre (CFF) as livestock waste in composite material development, International Journal of Water Resources, Vol.6, No.4, DOI; 10.4172/22525211.1000254

[4] El-Shekeil, Y. A., Sapuan, S. M., \& Algrafi, M. W. (2014). Effect of fiber loading on mechanical and morphological properties of cocoa pod husk fibers reinforced thermoplastic polyurethane composites. Materials \& Design, 64, 330-333.. https://doi.org/10.1016/j.matdes .2014.07.034

[5] Chun K.S., Husseinsyah S., Osman H. (2014). Development of biocomposites fromcocoa pod husk and polypropylene: Effect of filler content and 3-Aminopropy/triethoxy/silane, Polymers and Renewable Resources, Vol. 5, No. 4, 139-15. https://doi.org/10.1177/204124791400500401

[6] Chun, K. S., Huss einsyah, S., \& Osman, H. (2014). Development of biocomposites from cocoa podhusk and polypropylene: effect of filler content and 3-aminopropyltriethoxylsilane.Polymers from Renewable Resources, 5(4), 139-156. https://doi.org/10.1177/204124791400500401

[7] Chun, K. S., \& Husseinsyah, S. (2016). Agrowaste-based composites from cocoa pod husk and polypropylene: effect of filler content and chemical treatment. Journal of thermoplastic composite materials, 29(10), 1332-1351. https://doi.org/10.1177/0892705714563125

[8] Chun, K. S., Husseinsyah, S., \& Yeng, C. M. (2017). Torque rheological properties of polypropylene/cocoa pod husk composites. Journal of Thermoplastic Composite Materials, 30(9), 1217-1227. https://doi.org/10.1177/0892705715618743 
[9] Hemnath A., Anbuchezhiyan G., NanthaKumar P., Senthilkumar N. (2020). Tensile and flexural behaviour of rice husk and sugarcane bagasse reinforced polyester composites, Materials Today: Proceedings. https://doi.org/10.1016/j.matpr.2020.11.786

[10] Palanivendhan M., Chandaradass J., Philip J. (2020). Fabrication and mechanical properties of aluminium alloy/bagasse ash composite by stir casting method, Materials Today: Proceedings, https://doi.org/10.1016/j.matpr.2020.11.458

[11] Kumar P.V., Paranthaman P. (2020). Friction stir welding process parametric optimization of hybrid aluminium- bagasse ash-graphite composite by Tagu chi approach, Materials Today: Proceedings, Vol. 37, Part 2, 2021, 764-768. https://doi.org/10.1016/j.matpr.2020.05.789

[12] Kawin N., Jagadeesh D., Saravanan G., Periasamy K. (2020). Optimization of turning parameters in sugarcane bagasse ash reinforced with Al-Si10-Mg alloy composites by Taguchi method, Materials Today: Proceedings, 21, Part 1, 474-476. https://doi.org/10.1016/j.matpr.2019.06.634

[13] Bhat S.A., Singh J., Vig A.P. (2016). Management of sugar industrialwastes through vermitechnology, International Letters of Natural Science, 55, 35-43 DOI 10.18052/www.scipress.com/ILNS.55.35

[14] Bari M.N. , and Ahmed T. (2016). Characterization of sugar industry wastes for solid state bioconversion, Proceedings of the 3rd International Conference on Civil Engineering for Sustainable Development(ICCESD-2016), At:KUET, Khulna, Bangladesh. ISBN: 978-984-34-0265-3

[15] Ayanladun, C., \& Oke, S. (2020). A Sensitivity Analysis of Water Absorption Parameters of Theobroma Cacao L. Reinforced Epoxy Composites. Journal of Applied Science \& Process Engineering, 7(2), 587610.. https://doi.org/10.33736/jaspe.2604.2020

[16] Devadiga D.G., Bhat K.S. \& Mahesha G.T. (2020). Sugarcane bagasse fiber reinforced composites: Recent advances and applications, Cogent Engineering, 7(1), Article 1823159, DOI: 10:1080/233 11916. 2020.1823159

[17] Kiatkittipong W., Wongsuchoto P. \& Pavasant P. (2009). Life cycle assessment of bagasse waste management options, Waste Management, 29(5), 1628-1633. DOI: 10.1016/j.wasman.2008.12.006

[18] Abubakar M., El-Okene A.M., Buba A.N., Mohammed U.S. (2014).Investigation of properties of guinea fowl feather for engineering application, International Journal of Engineering Research and Technology, Vol. 3, No 5, 2484-2488. ISSN 2278-0181

[19] Verma A, Negi P. \& Singh V.K. (2018). Experimental investigation of chicken feather fibre and crumb rubber reformed epoxy resin hybrid composite: mechanical and microstructural characterization, Journal of the Mechanical Behaviour of Materials, Vol.27, No. 3-4, 1-24. DOI: 10.1515/jmbm-20180014

[20] Oladele, I. O., Okoro, A. M., Omotoyinbo, J. A., \& Khoathane, M. C. (2018). Evaluation of the mechanical properties of chemically modified chicken feather fibres reinforced high density polyethylene composites. Journal of Taibah University for Science, 12(1), 56-63. https://doi.org/10.1080/16583655.2018.1451103

[21] Taghiyari H.R, Majidi R., Esmail pour A. Samachi Y.S., Jahangiri A., Papadopoulos A.N. (2020). Engineering composites made from wood and chicken feather bonded with UF resin fortified with wollastonite: A novel approach, Polymers, Vol.12, Article 857, DOI: 10.3390/polym12040857

[22] Zhan M. and Wool R.P. (2016). Mechanical properties of composites with chicken feather and glass fibre, Applied Polymer Science, 133, Article 44013, DOI:10.1002/app. 44013.

[23] Suherman, H., \& Sahari, J. (2015). Optimization of Moulding Parameters on the Electrical Conductivity of Carbon Black/Graphite/Epoxy Composite for Bipolar Plateusing the Taguchi Method. In Advanced Materials Research(Vol. 1119, pp. 201-206). Trans Tech Publications Ltd. https://doi.org/10.4028/www.scientific.net/AMR.1119.201

[24] Kiran Z.S., Babu V.S., Sais rinadh K.V. (2018). Effect of nanoclay, glass fiber volume and orientation on tensile strength of epoxy-glass composite and optimization using Taguchi method, World Journal of Engineering, Vol. 15 No. 2, 312-320. https//doi.org/10.1108/W JE-08-2017-0286

[25] Pang J.S. , Ansari M.N.M., Zaroog O.S., Alim H. , Sapuan S.M. (2013). Taguchi design optimization of machining parameters on the $\mathrm{CNC}$ end milling process of halloysite nanotube with aluminum 
reinforced epoxy matrix (HNT/ALEP) hybrid composite, Housing and Building Research Center Journalhttp//dx.doi.org/10.1016/j.hbrcj.2013

[26] Bagci, M., \& Imrek, H. (2013). Application of Taguchi method on optimization of testing parameters for erosion of glass fiber reinforced epoxy composite materials. Materials \& Design, 46, 706-712. https://doi.org/10.1016/j.matdes.2012.11.024.

[27] Costa U.O., Naximento L.F.C. ,Garcial J.M., Bezerra W.B.A., Monteiro S.N. (2020). Evaluation of izod impact and bend properties of epoxy composites reinforced with mallow fibers, Journal of Materials Research and Technology, Vol. 9, No. 1, 373-382

[28] Wang Y., Yang H., Tian Z., Yang B., Xian G., Weng J., Chen S., Ding X., Luo W. (2020). Mode 1: Interlaminar crack length prediction by the resistance signal of the integrated MWCNT sensor in WGF/epoxy composites during DCB test, Journal of Materials Research and Technology, 9(3), 59225933. https://doi.org/10.1016/j.jmrt.2020.03.119

[29] da Costa Garcia Filho, F., da Luz, F. S., Oliveira, M. S., Pereira, A. C., Costa, U. O., \& Monteiro, S. N. (2020). Thermal behavior of graphene oxide-coated piassava fiber and their epoxy composites. Journal of Materials Research and Technology, 9(3), 5343-5351. https://doi.org/10.1016/j.jmrt.2020.03.060

[30] Ige O.E. I, Inambao F. L., Adewumi G. A. (2019). Biomass-based composites for brake pads: a review, International Journal of Mechanical Engineering and Technology, 10(3), 920-943. ISSN Online: 09766359

[31] Loh Y.R., Sujaria D, Rahman M.E., Das C.A. (2013). Sugarcane bagasse - The future composite material: A literature review, Resources, Conservation and Recycling, Vol. 75, 14-22.

[32] Xiong W. (2018). Bagasse composites: A review of material preparation, attributes, and affecting factors, Journal of Thermoplastic Composite Materials, Vol 31, No. 8, 1112-1146. DOI: $10.1177 / 08927057 / 7734596$.

[33] Vidyashri V., Lewis H., Narayanasamy P., Mahesha G.T., Bhat K.S. (2019). Preparation of chemically treated sugarcane bagasse fiber reinforced epoxy composites and their characterization, Cogent Engineering, Vol.,6, No., Article 1708644, DOI: 10.1080/23311916.2019.178644.

[34] Kumar, T. S., Shalini, S., Kumar, K. K., Thavamani, R., \& Subramanian, R. (2018). Bagasse Ash reinforced A356 alloy composite: synthesis and characterization. Materials Today: Proceedings, 5(2), 7123-7130.. https://doi.org/10.1016/j.matpr.2017.11.377

[35] Imo is ili, P. E., Ezenwafor, T. C., AttahDaniel, B. E., \& Olusunle, S. O. O. (2013). Mechanical properties of Cocoa-Pod/Epoxy composite; effect of filler fraction. American Chemical Science Journal, 3(4), 526531.

[36] Imoisili PE, Etiobho BW, Ezenwafor TC, Attah-Daniels BE, Olusunle S.O.(2013b). Physicochemical analysis of cocoa pod and its effect as a filler in polymer resin composite, International Journal of Science and Technology, Vol. 2, No. 1, 89-93.

[37] Imoisili P.E., Jiddah-KazeemB., Yahaya L.E. (2016). Kinetic studies on water absorption properties of cocoa-pod epoxy composites, Iranian Journal of Energy and Environment, Vol. 7, No. 1, 48-51

[38] Ramakrishnan S., Krishnamurthy K., Rajasekar R. and Rajeshkumar G. (2018). An experimental study on the effect of nano-clay addition on mechanical and water absorption behaviour of jute fibre rein forced epoxy compos ites, Journal of Industrial Textiles, 1-24. DOI: 10.1177/1528083718792915

[39] Mohammadi, M., Samadi, S., \& Najafpour Darzi, G. (2016). Production of single cell protein from sugarcane bagasse by Saccharomyces cerevisiae in tray bioreactor. International Journal of Engineering, 29(8), 1029-1036.

[40] MansurD., Tago T., Haznan T.M., Abimanyu A.H. 2014, Conversion of cacao pod husks by pyrolysis and catalytic reaction to produce useful chemicals, Biomass and Bioenergy, Vol. 66, 275-285. DOI: 10.1016/j.biombioe.2014.03.065

[41] Abubakar M., El-Okene A.M., Buba A.N., Mohammed U.S. (2014). Investigation of properties of guinea fowl feather for engineering application, International Journal of Engineering Research \& Technology, Vol. 3, No. 5, 2484-2488. ISSN 2278-0181

[42] Nwafor S., Oke S., Ayanladun C. (2019). Taguchi optimization of cast geometries for A356/organic particulate aluminiumalloy composites using a two-phase casting process, Journal of Applied Science \& Process Engineering, Vol. 6, No. 2, 386-411. DOI: https://doi.org/10.33736/jas pe.1722.2019 
[43] Ajibade O.A., Agunsoye J.O., Oke S.A. (2019). Optimis ation of water absorption parameters of dualfiller filled composites using Taguchi and moderated Taguchi techniques, Kufa Journal of Engineering, Vol. 10, No. 2, 134-151.

[44] Saxena M., Pappu A., Sharma A., HaqueR. and Wankhede S. (2011). Composite Materials fromnatural resources: Recent trend and future potentials, Chapter 6, Open Peer Reviewed Chapter, 121-162. IntechOpen Limited, London, UK. DOI: 10.5772/18264. 